Paul J. Young Michael Joannidis

\section{Crystalloid fluid therapy: is the balance tipping towards balanced solutions?}

Received: 19 October 2014

Accepted: 23 October 2014

Published online: 11 November 2014

(C) Springer-Verlag Berlin Heidelberg and ESICM 2014

\section{P. J. Young}

Intensive Care Unit, Wellington Regional Hospital,

Wellington, New Zealand

\section{P. J. Young}

Medical Research Institute of New Zealand, Wellington, New Zealand

M. Joannidis ( $\bullet$ )

Division of Intensive Care and Emergency Medicine, Department of Internal Medicine I, Medical University of Innsbruck, Innsbruck, Austria e-mail: michael.joannidis@i-med.ac.at

Intravenous saline solutions were first introduced into clinical practice in the Sunderland cholera epidemic of 1831 [1]. More than 150 years later, not only is $0.9 \%$ saline the most commonly used intravenous fluid in critically ill patients, it is also the fluid that has been administered to the largest number of critically ill patients in randomised controlled trials [2,3]. It is cheap and readily available, and more than a million litres of intravenous $0.9 \%$ saline are administered to patients around the world every day [1]; however, although it is widely known as 'normal saline', $0.9 \%$ saline is neither normal nor physiological [4]. In fact, the concentration of chloride in $0.9 \%$ saline is approximately 1.5 times that of normal plasma. Compared to low chloride solutions like Hartmann's, rapid infusion of $0.9 \%$ saline results in acidosis due to reduced strong ion difference, reduced renal perfusion and glomerular filtration rate, a tendency towards reduced urinary output, and even a pronounced increase in body weight $[5,6]$. Recent data raise the possibility that administration of $0.9 \%$ saline [7] may be harmful and suggest that using 'balanced' solutions with lower, more physiological, chloride concentrations than $0.9 \%$ saline may be preferable [8-10].

The relationship between the serum chloride concentration and outcome appears to be 'U-shaped' so that values outside of the normal physiological range are associated with an increased risk of death [11]. Positive fluid balance is also associated with an increased risk of death [12]. Because chloride loading and volume loading often occur together the relative contributions of chloride overload and volume overload to the apparent increased mortality risk are uncertain. In this issue of Intensive Care Medicine, Shaw and colleagues examine, among other things, the association between the 'volume-adjusted chloride load' and in-hospital mortality in more than 100,000 patients with tachycardia (heart rate over $90 \mathrm{bpm}$ ) and at least one other systemic inflammatory response syndrome (SIRS) criterion [13]. The purpose of this was to demonstrate the association between chloride administration and outcome independent of administered fluid volume. In doing so, Shaw and colleagues were able to demonstrate, for the first time, an association between increasing amounts of chloride administered during crystalloid resuscitation and increased in-hospital mortality which persisted after controlling for the total volume of fluid administered [13], raising the possibility that the chloride content of resuscitation fluids might be a modifiable risk factor for adverse outcomes.

This study adds to previous data which demonstrated an association between the use of chloride-rich fluids and adverse outcomes compared to the use of balanced solutions in surgical patients [9] and patients with sepsis [10] and is consistent with a single centre, open label, beforeand-after period pilot study which showed that a strategy 
Table 1 Electrolyte composition and osmolality of commonly used crystalloids

\begin{tabular}{|c|c|c|c|c|c|c|}
\hline & \multicolumn{6}{|c|}{ Concentration $(\mathrm{mmol} / \mathrm{l})$} \\
\hline & Plasma & $\mathrm{NaCl} 0.9 \%$ & Ringer's lactate & ELO-MEL isoton ${ }^{\circledR}$ & Plasma-Lyte $148^{\circledR}$ & Sterofundin ${ }^{\circledR}$ \\
\hline Sodium (mmol/1) & 140 & 154 & 131 & 140 & 140 & 145 \\
\hline Potassium (mmol/l) & 5 & 0 & 5 & 5 & 5 & 4 \\
\hline Chloride (mmol/l) & 100 & 154 & 112 & 108 & 98 & 127 \\
\hline Calcium (mmol/l) & 2.2 & 0 & 2 & 2.5 & 0 & 2.5 \\
\hline Magnesium (mmol/l) & 1 & 0 & 0 & 1.5 & 1.5 & 1 \\
\hline Bicarbonate $(\mathrm{mmol} / \mathrm{l})$ & 24 & 0 & 0 & 0 & 0 & 0 \\
\hline Lactate $(\mathrm{mmol} / \mathrm{l})$ & 1 & 0 & 28 & 0 & 0 & 0 \\
\hline Acetate $(\mathrm{mmol} / \mathrm{l})$ & 0 & 0 & 0 & 45 & 27 & 24 \\
\hline Gluconate (mmol/l) & 0 & 0 & 0 & 0 & 23 & 0 \\
\hline Malate (mmol/l) & 0 & 0 & 0 & 0 & 0 & 5 \\
\hline Osmolarity (mosmol/l) & $280-296^{\mathrm{a}}$ & 308 & 278 & 302 & 295 & 309 \\
\hline
\end{tabular}

Ringer's lactate (Hartmann's), Plasma-Lyte $148^{\circledR}$ and ELO-MEL Baxter (Deerfield, IL, USA) and Sterofundin ${ }^{\circledR}$ from B Braun isoton ${ }^{\circledR}$ may be considered more "balanced" with regard to chloride concentration. Ringers Lactate and ELO-MEL isoton ${ }^{\circledR}$ were from Fresenius Kabi (Graz, Austria), Plasma-Lyte $148^{\circledR}$ from

of avoiding chloride-rich fluid improved renal outcomes [8]. Overall, it appears that the association between the administration of chloride-rich fluids and adverse outcomes is robust, reproducible and most likely "dose dependent". Although the hypothesis is that chloride administration is harmful, the authors themselves acknowledge that the effects of sodium and chloride administration are difficult to tease apart. Their data indicate that in patients receiving fluid volumes greater than $3,000 \mathrm{ml}$, increased mortality may occur also with volume-adjusted sodium load with the lowest risk being seen in the range of 135-145 mmol/l. This is consistent with previous data showing that acquired hypernatraemia is associated with adverse outcomes [14]. Shaw's study, like almost all previous studies comparing $0.9 \%$ saline to balanced crystalloids, is highly subject to confounding. There may well be systematic differences, beyond the use of $0.9 \%$ saline vs. balanced crystalloids, between the types of patients who receive higher vs. lower 'volume-independent chloride loads'. Similarly, the treatment provided by doctors who chose to administer fluids with lower chloride concentrations may be systematically different to that provided by doctors using $0.9 \%$ saline. These factors may not be captured in a database and cannot be controlled for in a retrospective study. Finally, it must be considered that overall mortality in the investigated cohort was low and when performing a multivariate analysis the increased risk of mortality was around $1 \%$ (OR 1.011, CI 1.008-1.014) when volume-adjusted chloride load was greater than $110 \mathrm{mmol} / \mathrm{l}$.

Despite this, the hypothesis that balanced crystalloids offer a safer alternative to fluid resuscitation than $0.9 \%$ saline is a compelling one and, with this hypothesis in
(Melsungen, Germany)

${ }^{\text {a }} \mathrm{mosmol} / \mathrm{kg}$

mind, a co-ordinated programme of interventional studies comparing $0.9 \%$ saline to a balanced solution is underway in Australia and New Zealand. The first of the studies making up this programme, the SPLIT trial, compared $0.9 \%$ saline to Plasma-Lyte ${ }^{\circledR} 148$ for ICU fluid therapy in more than 2,000 patients and completed recruitment on 14 October 2014 [15]. This study should be reported by mid 2015 and will provide greater clarity in this area. Another unresolved issue is which anion to use instead of chloride. Some balanced solutions use lactate, others acetate or combinations of acetate and malate (Table 1). Whether the type of anion (buffer) makes any difference is largely unknown. When orienting at plasma composition it should probably be bicarbonate; however, this would require a more complicated and thus costly production process (i.e. two-chamber systems) to ensure stability.

Until large-scale randomised trials demonstrate that balanced crystalloids are superior to $0.9 \%$ saline, clinicians should remain sceptical and equipoise should persist. While some may chose to use balanced crystalloids in preference to $0.9 \%$ saline, those who chose to continue to use $0.9 \%$ saline should reassure themselves that their practice is supported by 150 years of clinical experience [1] and that more 7,000 ICU patients have received $0.9 \%$ saline in randomised controlled trials $[2$, 3].

Conflicts of interest Dr Young reports the receipt of an honorarium of less than $1,500 €$ from Baxter for consulting activities. Dr Young is the Chief Investigator for the SPLIT study which is an investigator-initiated study funded by the Health Research Council of New Zealand and Baxter Healthcare. Dr Joannidis reports receipt of a speaker's honorarium of less than $1,500 €$ from Baxter Healthcare. 


\section{References}

1. Awad S, Allison SP, Lobo DN (2008) The history of $0.9 \%$ saline. Clin Nutr 27(2):179-188 (Epub 2008/03/04)

2. Myburgh JA, Finfer S, Bellomo R, Billot L, Cass A, Gattas D et al (2012) Hydroxyethyl starch or saline for fluid resuscitation in intensive care. NEJM 367(20):1901-1911 (Epub 2012/10/19)

3. Finfer S, Bellomo R, Boyce N, French J, Myburgh J, Norton R (2004) A comparison of albumin and saline for fluid resuscitation in the intensive care unit. New Engl J Med 350(22):2247-2256 (Epub 2004/05/28)

4. Wakim KG (1970) "Normal" 0.9 per cent salt solution is neither "normal" nor physiological. JAMA 214(9):1710 (Epub 1970/11/30)

5. Scheingraber S, Rehm M, Sehmisch C, Finsterer U (1999) Rapid saline infusion produces hyperchloremic acidosis in patients undergoing gynecologic surgery. Anesthesiology 90(5):1265-1270 (Epub 1999/05/13)

6. Reid F, Lobo DN, Williams RN, Rowlands BJ, Allison SP (2003) $(\mathrm{Ab})$ normal saline and physiological Hartmann's solution: a randomized double-blind crossover study. Clin Sci (Lond) 104(1):17-24 (Epub 2003/01/ 10)

7. Yunos NM, Bellomo R, Story D, Kellum J (2010) Bench-to-bedside review: chloride in critical illness. Crit Care 14(4):226 (Epub 2010/07/29)
8. Yunos NM, Bellomo R, Hegarty C, Story D, Ho L, Bailey M (2012) Association between a chloride-liberal vs chloride-restrictive intravenous fluid administration strategy and kidney injury in critically ill adults. JAMA 308(15):1566-1572 (Epub 2012/10/18)

9. Shaw AD, Bagshaw SM, Goldstein SL, Scherer LA, Duan M, Schermer CR et al (2012) Major complications, mortality, and resource utilization after open abdominal surgery: $0.9 \%$ saline compared to Plasma-Lyte. Ann Surg 255(5):821-829 (Epub 2012/04/04)

10. Raghunathan K, Shaw A, Nathanson B, Sturmer T, Brookhart A, Stefan MS et al (2014) Association between the choice of IV crystalloid and in-hospital mortality among critically ill adults with sepsis. Crit Care Med 42(7):1585-1591 (Epub 2014/03/29)

11. McCluskey SA, Karkouti K, Wijeysundera D, Minkovich L, Tait G, Beattie WS (2013) Hyperchloremia after noncardiac surgery is independently associated with increased morbidity and mortality: a propensitymatched cohort study. Anesth Analg 117(2):412-421 (Epub 2013/06/130)

12. Boyd JH, Forbes J, Nakada TA, Walley KR, Russell JA (2011) Fluid resuscitation in septic shock: a positive fluid balance and elevated central venous pressure are associated with increased mortality. Crit Care Med 39(2):259-265 (Epub 2010/10/27)
13. Shaw AD, Raghunathan K, Peyerl FW, Peyeri FW, Munson SH, Paluszkiewicz SM, Schermer CR (2014) Association between the intravenous chloride load and in-hospital mortality among resuscitated patients with SIRS. Intensive Care Med. doi: 10.1007/s00134-014-3505-3

14. O'Donoghue SD, Dulhunty JM, Bandeshe HK, Senthuran S, Gowardman JR (2009) Acquired hypernatraemia is an independent predictor of mortality in critically ill patients. Anaesthesia 64(5):514-520 (Epub 2009/05/06)

15. Reddy S, Bailey M, Beasley R, Bellomo R, Henderson S, Mackle D, McArthur C, Mehrtens J, Myburgh J, McGuinness S, Psirides A, Young P (2014) The SPLIT study: a protocol for a multicentre cluster-randomised double crossover study of $0.9 \%$ saline vs. Plasma-Lyte $148^{\circledR}$ for intensive care fluid therapy. Crit Care Resusc 16(4):274-279 